\title{
Prototype of LPG gas leakage detector using flame sensor and MQ-2 sensor
}

\author{
Harya Gusdevi, Ade Setya $P$ and Puji Handini Zulaeha \\ Sekolah Tinggi Teknologi Bandung Jalan Soekarno Hatta No 378, Bandung, Indonesia
}

\begin{abstract}
Article Info
Article history:

Received Jan 22, 2019

Revised Nov 29, 2019

Accepted Jan 5, 2020

\section{Keywords:}

Android

Relay 4 channel

Sensor

Solenoid valve

ABSTRACT

The conversion of kerosene uses in household to gas, in addition to the decision of the Republic of Indonesia minister in relation to the movement of kerosene to gas, gas also given an affordable price, how to use it more effectively. But the public is also expected to be careful about how to use it, because the gas is explosive and leaking causing unpleasant odor (gas leak) even a more dangerous side effect is the explosion of gas cylinders. To evercome these problems then need a tool that can detect gas leakage, in order to prevent gas leakage early. Therefore, the authors designed a device that can detect gas leakage by using Sensor Mq-2 and will issue sound gas alarm warning leak by Modul ISD 1760, and will stop the gas flow from the tube to the stove using a Solenoid Valve. There is also a Flame Sensor's hardware to detect a fire if there is a spark emerging and spraying water into spots that are likely to spark fire. All hardware will be in if using ATMega 328microcontroller.Monitoring can use android smartphone, with the application that can send a warning to the mobile phone.
\end{abstract}

This is an open access article under the CC BY-SA license.

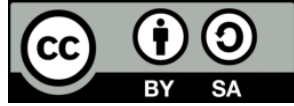

\section{Corresponding Author:}

Harya Gusdevi,

Sekolah Tinggi Teknologi Bandung,

Jalan Soekarno Hatta No 378, Bandung, Jawa Barat, Indonesia.

Email: Devi@sttbandung.ac.id

\section{INTRODUCTION}

The "smarthouse" technology is one realization of home automationideals using a specific set of technologies. It's a house that hashighly advanced automatic systems for lighting, temperaturecontrol, security, appliances, and many other functions. Codedsignals are sent through the home's wiring to switches andoutlets that are programmed to operate appliances andelectronic devices in every part of the house. Smart homeappears "intelligent" because its computer systems can monitormany aspects of daily living. Smart house can also provide a remote interface to home appliances or theautomation system itself, viatelephone line, wireless transmissionor the internet and android application, to providecontrol and montoring via a smart phone or web browser.

One problem that arises is part of the kitchen. Where is the important kitchen in the house. Many activities are carried out in the kitchen, such as cooking, washing etc. Cooking is a routine activity carried out by housewives. Cook for a long time or simple cooking with a short time. This must be considered by housewives. Cooking related to gas and fire. This can trigger a fire.

LPG gas has a shortage in starting using them compared petroleum which will burn if it is triggered by a fire that was nearby. LPG gas storage areas should use a tube that is strong and not easy to leak. Because if the storage tube gas leaked at the time used will be flammable. As for the kerosene storage could use a conductor or a used bottle. 
Liquefied Petroleum Gas (LPG) is a by product of natural gas extraction and crude oil refining. It is considered a clean and environmentally-friendly source of energy. If made available as a cooking energy fuel it could help to reduce the negative health impacts of 2.6 billion people who currently use biomass stoves that emit harmful smoke and particles due to incomplete combustion [1].

The potential of an increased use of LPG as a cooking fuel is known for several years now. In 2001, a joint study of the World Bank and World LPG Association (WLPGA) described the potential of LPG: Liquefied Petroleum Gas (LPG) is a clean and environmentally-friendly source of energy. To protect the environment, LPG could be made available to replace wood and biomass in all households in all developing countries [2].

LPG gas that began much used by people not worth the gas cylinder producers who experience a decrease in terms of quality, so that it can cause hazard due to the lack of supervision of the gas tube products. Since the Government is planning the conversion of kerosene to LPG gas lots of events hit the gas tubes are hazardous to people or the surrounding communities. Proven in field found a broken tube, easily corroded, dented, so it is very prone to LPG gas leaks in the tubes.

Therefore this research wants to provide solutions on how these problems can be anticipated with LPG gas leaks in the gas cylinder by a gas sensor using a microcontroller and if they meet the conditions of detection has been determined, then it can give a warning beep first response when the condition of the gas leak, after 3 minutes there is no response from the user then a second beep alarm will appear with a greater voice, and the solenoid will be activated with the help of the relay to cut off the gas supply from the tube to the next burner if the sparks began to emerge then the fire sensor. Flame sensor will read it and will automatically be doused water towards the Sparks to minimize fire that will progressively enlarged.

In this study will be discussed about smart kitchens such as LPG Gas leakage detectors using fire sensors and MQ-2. Where to provide solutions to how the problem can be anticipated with the LPG gas leakage equipment on gas cylinders by the MQ-2 sensors that are processed using microcontrollers and solenoid will be active with the help of the relay to cut off the gas supply from Tube to the stove next if the sparks begin to appear then the fire sensor that is the Flame sensor will read it and will automatically be watered by the water sparks to minimize the flames will be enlarged.

\section{RESEARCH METHOD}

In the implementation of the research, and to facilitate solve the problems faced, it is necessary to first describe the steps needed to solve the problem. This chapter contains a thorough explanation of the problem-solving stages used in this research. The main purpose is to clarify the scope and steps - steps needed at each stage of the research. The stages of the methodology of this study are illustrated as in Figure 1 which shows the research methodology in the form of diagram.

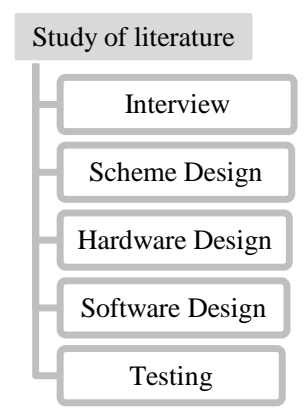

Figure 1. Research method

Design research required in conducting research and manufacture of this tool, including the following activities:

a. Study of literature

The use of literature in this process is done by studying concepts, data collection, in the form of theory and material, sourced from books, journals, and other sources on matters relating to the development of tools to be designed.

b. Interview

Interviews with users of gas cylinders to obtain information on the problems and expected solutions. 
c. Scheme Design

Designing schemes created as objects of analysis of the possibilities that occur when a tool is created. This is done to minimize the error of connecting some modules that are combined in a microcontroller.

d. Hardware Design

The design of hardware is done by connecting some sensor module used in ATMega328 microcontroller.

e. Software Design

Software design is the writing of program code that is used to make instruction to every hardware component.

f. Testing

The test is done to know each component functioning or not functioning.

\subsection{Method of data collection}

Data collection was conducted in order to obtain the information needed to solve the problems that lead to an engineering. The research methodology used is as follows:

a. Literature Study

The use of literature in this process is done by studying the concepts, data collection, in the form of the theory as well as material, sourced from books, journals, and other resources on matters related to the development of tools that will be designed.

b. Interview

Conducted a series of discussions with the users of the gas tube to get information the problems that occur and the expected solution

c. Literature Studies

The use of literature in this process is done by studying the concepts, the collection of knowledge in the form of theory and materials, sources of books or other literature on matters relating to LPG Gas Leakage Detector Using Flame Sensor AndMQ-2 Sensor or anything that leads to the solution problem.

\subsection{Systems development method}

Development methods used in the manufacture of prototype LPG Gas Leakage Detector Using Flame Sensor and Solenoid Valve Based Microcontroller This is a prototype method, namely development methods and consumers can interact during the process of making the tool. The prototype method, starting with the collection of customer needs on the tool to be created, defines the overall objective of the hardware and software, identifies all the needs, and then "flash design" is focused on presenting the necessary aspects to make the customer more imaginative with what is actually desired. Figure 2 shows about systems development method.

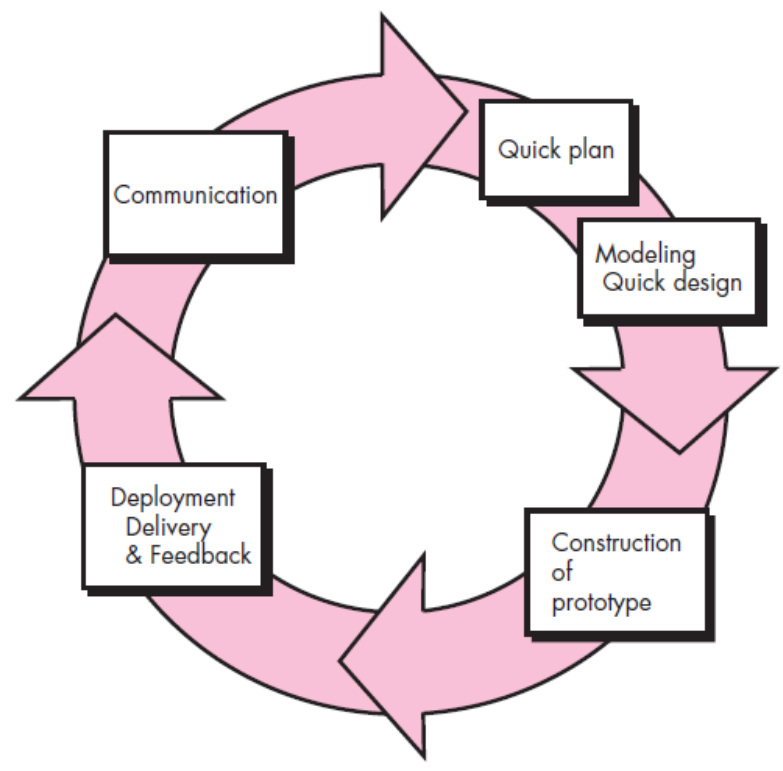

Figure 2. Systems development method [3] 


\subsection{Literatur review}

First paper explained [4] that the a wireless safety device for gas leakage detection is proposed. The device is intended for use in household safety where appliances and heaters that use natural gas and liquid petroleum gas (LPG) may be a source of risk. The system also can be used for other applications in the industry or plants that depend on LPG and natural gas in their operations. The system design consists of two main modules: the detection and transmission module, and the receiving module. The detection and transmitting module detects the change of gas concentration using a special sensing circuit built for this purpose. This module checks if a change in concentration of gas(es) has exceeded a certain pre-determined threshold. If the sensor detects a change in gas concentration, it activates and audiovisual alarm and sends a signal to the receiver module. The receiver module acts as a mobile alarm device to allow the mobility within the house premises. The system was tested using LPG and the alarm was activated as a result of change in concentration. Second paper explained [5] that The issue of plant explosion due to gas leakage is a serious problem which impacts the lives of the personnel, damages plant equipments and incurs high cost for maintenance. As this issue is a high risk at hazardous place such as a combustible gas plant, there is an important need to use gas detector which functions to detect gas leakage at a particular area. However, some gas detectors are less reliable in detecting gas due to presence of other unwanted elements which may cause the instruments to malfunction. The objective of the study is to eliminate those unwanted elements in order to maintain the well functioning of the instrument. The paper discusses the Infrared signal absorption by combustible gas and solution to eliminate moisture trapped in gas detector. Third paper explained [6] that This project focuses on developing an electronic system that detects gas leakage and smoke giving visual level indication using LEDs. In case of high concentration gas or smoke detected, the system wirelessly activates a relay to switch off the mains thus preventing a major possibility of fire accident and also gives audio alarm for the same. The analog voltage values equivalent of smoke and gas concentration detected are wirelessly transmitted to be displayed on a computer screen periodically. The system is advantageous compared to the existing systems in the way that it is a battery powered, smart standalone module that does not require human intervention.

The difference of the 3 papers with this research is first paper explained audiovisual alarm and sends a signal to the receiver module. The receiver module acts as a mobile alarm device to allow the mobility within the House premises. Use MQ-5 sensor normalized to the resistance sensor Ro at 1000 ppm of H2 in water. The sensor can detect small concentrations of the above mentioned gases as small as $0.1 \mathrm{mg} / \mathrm{L}$. Second Paper explained about discusses the Infrared signal absorption by combustible gas and solution to eliminate moisture trapped in gas detector. Third Paper explained about This Project focuses on developing an electronic system that detects gas leakage and smoke giving visual level indication using LEDs. While This paper explained about smart kitchens such as LPG Gas leakage detectors using fire sensors and MQ-2. Where to provide solutions to how the problem can be agreement with the LPG gas leakage equipment on gas cylinders by the MQ-2 sensors that are processed using microcontrollers and solenoid will be active with the help of the relay to cut off the gas supply from Tube to The stove next if the sparks begin to appear then the fire sensor that is the Flame sensor will read it and will automatically be watered by the water sparks to minimize the flames will be enlarged.

\section{RESULTS AND ANALYSIS}

3.1. System analysis

Design of research conducted in the completion of this research includes the design of hardware or hardware.

\subsubsection{Software analysis}

Design and manufacture of LPG gas leak detector using flame sensor and solenoid valve based on microcontroller ATMega 328 there are some software used are as follows on Table 1.

Table 1. Software analysis

\begin{tabular}{cc}
\hline No & Name \\
\hline 1 & Software Arduino 1.8.2 \\
2 & Software Fritzing \\
3 & CorelDraw Graphics Suite X4 \\
4 & Android Studio \\
\hline
\end{tabular}




\subsubsection{Hardware analysis}

The following components or materials used in the design and manufacture of LPG gas leak detection equipment using flame sensors and solenoid valve-based microcontroller ATMega 328 are presented in Table 2.

\begin{tabular}{ccc}
\multicolumn{3}{c}{ Table 2. Hardware } \\
\hline No & Component & Number \\
\hline 1 & Sensor MQ-2 & 1 \\
2 & Flame Sensor & 2 \\
3 & Modul ISD 1820 + Speaker & 1 \\
4 & Solenoid Valve & 2 \\
5 & Relay 4 Channel & 1 \\
6 & Bread Board & 1 \\
7 & ArduinoUnoModul & 1 \\
8 & Jumper male to male cable & 3 \\
9 & Jumper male to female cable & 3 \\
10 & Green Led, Blue Led, white Led & 3 \\
11 & Adaptor 5V & 1 \\
12 & Connectors Solenoid Valve & 2 \\
13 & Power Supply 24v & 1 \\
14 & USB Supply Arduino Cable & 1 \\
15 & Portable Stove & 1 \\
16 & Gas Cylinders & 1 \\
17 & Water Hose Diameter 4mm & 1 \\
18 & Single Cable & 3 \\
\hline
\end{tabular}

\subsubsection{Tool overview}

The design and manufacture of LPG gas leak detector using ATMega 328 microcontroller which has the function as a processor from the input of both sensors ie, sensor mq-2 and flame sensor into several outputs. This tool will be active in its entirety if the indicator light is on as an indicator if it is active, and the gas sensor will read if there is a gas leak and transmit it to ATMega 328 microcontroller, then output from the microcontroller ie activate the solenoid to normally close, and issue a sound warning that gas is leaking from the ISD1820 module. The fire sensor will be active if there is a spark and the microcontroller will activate the solenoid valve to normally open and flush water into the spark. Monitoring can use android smartphone, with the application that can send a warning to the mobile phone.

\subsubsection{Block diagram}

The block diagram is structured to facilitate the understanding of the overall workings of the entire designed circuit. From the mas-ing each block diagram created has different functions depending on how the circuit is designed, so that when combined several block diagrams will produce a working system that works in stages with more complex functions. The following block diagram in the planning and manufacture of LPG gas leak detection equipment using flame sensors and micro-controller solenoid valve of ATMega 328 is presented in Figure 3.

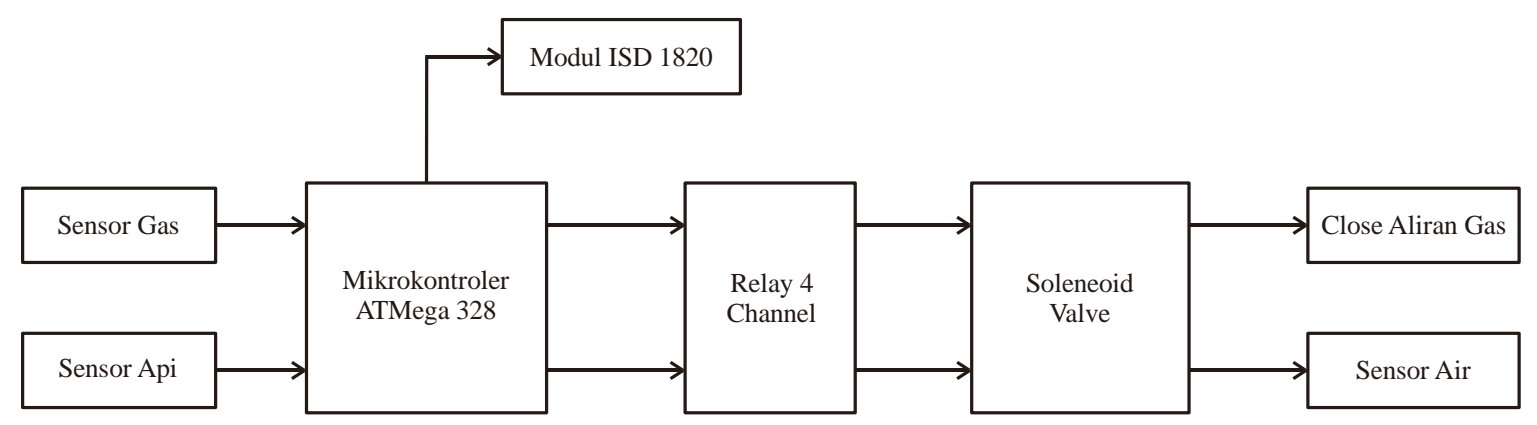

Figure 3. Block Diagram 


\subsubsection{The principle of work tools}

The working principle is a tool designed in the preparation of this reserarch are as follows:

a. When the sensor detects the gas leak gas or smoke will then be used as the input to be sent to the microcontroller to be processed into several output, one of the outputs will use the relay which will serve to supplement the power needed solenoid.

b. Solenoid active according to command "normally open or normally closed" when one of the active sensor.

c. A warning sound to let users know if a gas leak i.e. presence of alarm sound from the sound module ISD 1820. All these instructions are stored in the microcontroller ATMega 328.

\subsection{Design system}

The main objective of the design of the system is to provide an overview of the design of the system to be built or developed, as well as to understand the flow of information and processes in the system as shown in Figure 4. The following specified stages or steps to be made in the design of the system:

a. Sensor MQ-Series 2

b. The circuit module ISD 1820

c. The series of sensor API

d. Circuit Relay 4 Channel

e. Circuit Relay 4 Channel to the Solenoid Valve

Aside from the stages of design that has been described above, there are specifications of the tool used in the design and manufacture of gas leakage detector tool using the flame sensor and solenoid valve ATMega microcontroller-based This 328 of which were as follows:

a. There are two modules modules i.e. the Arduinouno and voice module ISD 1760.

b. There are also two sensors namely gas sensor MQ-2 and sensor APIs.

c. Use a Solenoid Valve

d. Use the 4 Channel Relay

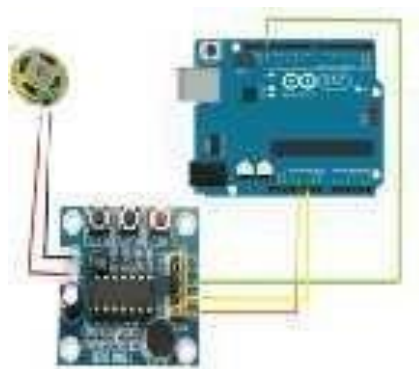

Modul ISD 1760

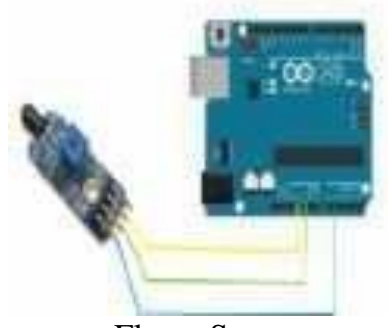

Flame Sensor

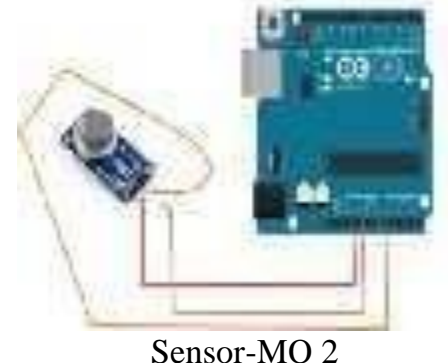

Sensor-MQ 2

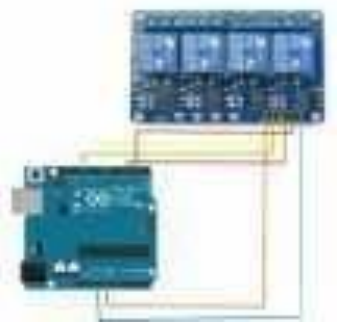

Relay 4 Channel

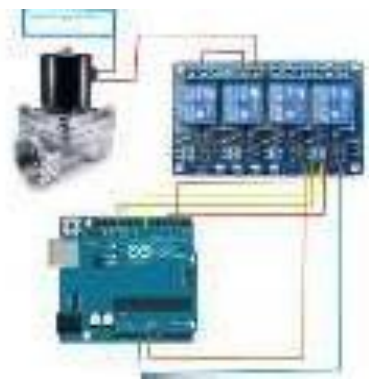

Solenoid Valve For fire

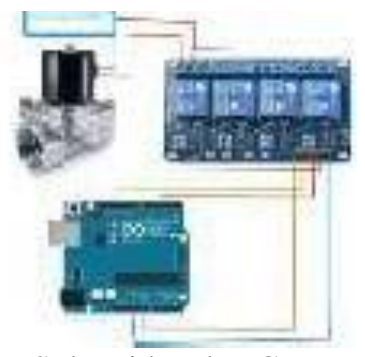

Solenoid Valve Gas

Figure 4. Set of tools

\subsection{System implementation}

The system implementation stage is based on the results obtained in system design. Making this tool starts with the process of system analysis, scheme design, hardware design, software design and tool testing. Testing tool is done by identifying problems that arise when the device is operated, in order to be repaired so that in accordance with the needs of users and the process flow that has been determined. Figure 5 shows connection to android smartphone. 

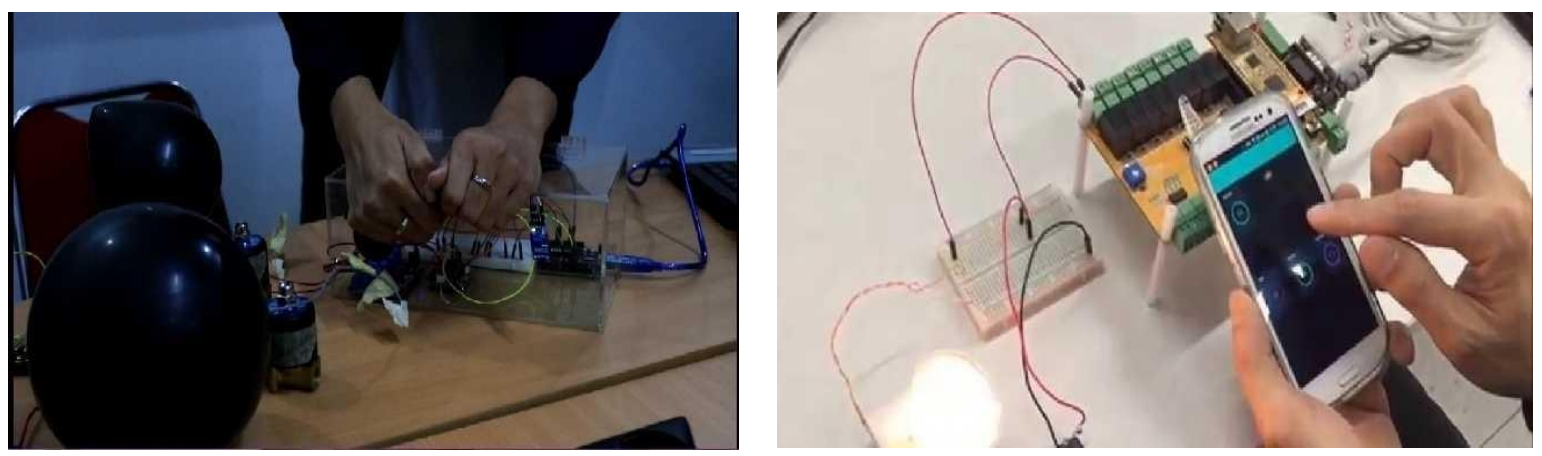

Figure 5. Connection to android smartphone

\subsection{Testing tools}

This test is done to ensure that the tool has been designed to function properly and in accordance with the goal.

\subsubsection{Gas sensor testing MQ-2}

The test of the gas sensor mq-2 is through the sensitivity level of the gas sensor by looking at the serial monitor in arduinouno software. Data will be presented in Table 3.

Table 3. Result test sensitivity of gas sensor MQ-2

\begin{tabular}{|c|c|c|c|}
\hline \multicolumn{4}{|c|}{ Result Test Gas Sensor MQ-2 } \\
\hline Test Scenario & Expected Results & Observation & Result \\
\hline A surge of gas amounted to 215 & $\begin{array}{c}\text { Solenoid Valve is still in NO state and } \\
\text { sound alarm does not sound }\end{array}$ & Relay1 is on (Solenoid NO), Alarm Off & $\mathrm{OK}$ \\
\hline A surge of gas amounted to 228 & $\begin{array}{c}\text { Solenoid Valve is still in NO state and } \\
\text { sound alarm does not sound }\end{array}$ & Relay1 is on (Solenoid NO), alarm off & $\mathrm{OK}$ \\
\hline A surge of gas amounted to 413 & $\begin{array}{c}\text { Solenoid Valve change to be NC and } \\
\text { alarm ON }\end{array}$ & Relay1 Off, (Solenoid NC), alarm ON & $\mathrm{OK}$ \\
\hline A surge of gas amounted to 436 & $\begin{array}{c}\text { Solenoid Valve change to be NC and } \\
\text { alarm ON }\end{array}$ & Relay1 Off, (Solenoid NC), alarm ON & $\mathrm{OK}$ \\
\hline A surge of gas amounted to 429 & $\begin{array}{c}\text { Solenoid Valve change to be NC and } \\
\text { alarm ON }\end{array}$ & Relay1 Off, (Solenoid NC), alarm ON & $\mathrm{OK}$ \\
\hline A surge of gas amounted to 241 & $\begin{array}{c}\text { Solenoid Valve is still in NO and } \\
\text { sound alarm dosen not sound }\end{array}$ & Relay 1 ON (Solenoid NO), alarm Off & $\mathrm{OK}$ \\
\hline
\end{tabular}

\section{CONCLUSION}

Based on the research, design, and manufacture of the tool then it can be taken a few conclusions are as follows. This detection Tool can help users through alarm sounds and disconnection of gas flow in anticipation of the beginning if the absence of action from the user to minimize the presence of sparks. The solenoid is very useful on this device because doing first aid if the gas sensor detects gas leaks then solenoid will decide on gas flow, by contrast with the usefulness of the solenoid to fire sensor open water flow if the flame sensor detect any spark. Notification by the alarm sound very helpful users if the user is not sensitive to the smell of leaking gas, then the user can know of any gas leaks through the alarm sound.

\section{REFERENCES}

[1] https://energypedia.info/wiki/Liquefied_Petroleum_Gas_(LPG)

[2] World Bank Und WLPGA, 2001, http://documents.worldbank.org/curated/en/2013/01/18612457/west-africaliquefied-petroleum-gas-lpg-market-development-study

[3] Pressman RS. Software Engineering: A Practitioner's Approach, 7th ed.Mc Grow Hill.2010.

[4] Luay Fraiwan, Khaldon Lweesy, Aya Bani-Salma, Nour Mani, "A wireless home safety gas leakage detection system”, 2011 1st Middle East Conference on Biomedical Engineering, 21-24 Feb. 2011.

[5] Nur Malissa Binti Nasaruddin, Irraivan Elamvazuthi, Noor Hazrin Hany Binti Mohd Hani, "Overcoming Gas Detector Fault Alarm Due To Moisture", Proceedings of 2009 IEEE Student Conference on Research and Development (SCOReD 2009), 16-18 Nov. 2009, FPM Serdang, Malaysia.

[6] Nivedhitha S, Padmavathy A P, Susaritha U S Mentor: Dr. M. Ganesh Madhan, "Development of Multipurpose Gas Leakage and Fire Detector with Alarm System”, 2013 Texas Instruments India Educators' Conference. 